\title{
Expanding the spectrum of A20 haploinsufficiency in two Chinese families: cases report
}

\author{
Guo-min Li', Hai-mei Liu', Wan-zhen Guan', Hong Xu', Bing-bing Wu² and Li Sun ${ }^{1 *}(\mathbb{D}$
}

\begin{abstract}
Background: The association between mutations in the TNFAIP3 gene and a new autoinflammatory disease (called A20 haploinsufficiency, HA20) has recently been recognized. Here, we describe four patients with HA20 from two unrelated Chinese families.

Case presentation: A total of four patients from two families were included. The average age at onset was 5.9 years. All patients had no signs of eye or skin problems, such as uveitis, rash, folliculitis and dermal abscess. Prior to the recognition of HA20, P1 was diagnosed with SLE, liver fibrosis and hypothyroidism. She also had no oral, genital or perineal ulcers. P2 was diagnosed with Crohn's disease and inflammatory bowel disease-related arthritis (IBD-RA). He had a perianal abscess but no oral or genital ulcers. P3, the father of P1 and P2, only had mild oral ulcers, arthralgia, and archosyrinx. P4 was diagnosed with polyarticular juvenile idiopathic arthritis (JIA), macrophage activation syndrome (MAS) and interstitial lung disease (ILD). Whole exome sequencing (WES) was performed in two families. WES revealed heterozygous C.559C > T in the TNFAIP3 gene in P1, P2 and P3, while the c.259C > T mutation in the TNFAIP3 gene was identified in P4. The c.259C > T mutations is novel.
\end{abstract}

Conclusion: HA20 had a different phenotype between families and even between family members with the same mutation. Liver fibrosis, hypothyroidism, ILD and MAS in the patients with HA20 were first reported in this study. Our results expanded the phenotype and genotype spectrum of A20 haploinsufficiency.

Keywords: A20 haploinsufficiency, Hypothyroidism, Interstitial lung disease, Liver fibrosis, Macrophage activation syndrome, TNFAIP3 gene

\section{Background}

The TNFAIP3 gene that encodes the $90 \mathrm{kDa}$ A20 protein was first described in 1990 as a TNF- $\alpha$-induced primary response gene in endothelial cells [1]. The protein A20 is a negative regulator of the TNF-nuclear factor-kB signaling pathway, which plays fundamental roles in various physiological and pathological processes, such as immunity, apoptosis, inflammation, and cancer [2, 3]. Polymorphisms in TNFAIP3 have been linked to the development of several autoimmune and autoinflammatory diseases in genome-wide association studies, such as systemic lupus erythematosus [4-6], Sjögren's Syndrome [7], Crohn disease [8], rheumatoid arthritis [9, 10], type

\footnotetext{
* Correspondence: lillysun@263.net

'Department of Rheumatology, Children's Hospital of Fudan University, 399

Wan-yuan road, Shanghai 201102, China

Full list of author information is available at the end of the article
}

1 diabetes [11] and psoriasis [12]. Recently, heterozygous germline mutations in the TNFAIP3 gene have been found to cause the haploinsufficiency of A20 (HA20), which displays an early-onset autoinflammatory disease resembling Behçet's disease [13]. HA20, first described by Zhou et al. in 2016, is a new autoinflammatory disease [13]. Zhou et al. found that the major phenotype of HA20 displays Behçet's disease-like symptoms, including recurrent aphthous stomatitis, genital ulcers, and intestinal symptoms [13]. However, a number of studies showed that some patients present with not only the features of autoinflammatory diseases but also several autoimmune-like features [14-17]. Therefore, these preceding clinical reports suggested that there might be unexpected phenotypes in HA20. Cases with HA20 were not reported in China. In this study, we described four patients in two HA20 families, which 
were diagnosed by whole exons sequencing, to enrich the phenotype and genotype spectrum of HA20.

\section{Case presentation}

Two unrelated families with HA20 were enrolled in this study (Fig. 1). All adults provided written informed consent.

\section{Family 1}

The proband 1 (P1), a 14-year-old Chinese girl, presented with abdominal swelling at the age of 7 . She went to her local hospital, and ultrasound showed hepatomegaly, ascites and pericardial effusion. Laboratory findings suggested dysfunction of the liver and thyroid. Therefore, hepatic fibrosis, pericardial effusion and hypothyroidism were diagnosed. She was referred to our hospital for evaluation because of the continued hepatomegaly with hepatic dysfunction for 4 years and intermittent fever for 6 months at the age of 11. Laboratory testing revealed leukopenia, anemia, thrombocytopenia, hematuria, proteinuria, low levels of complement, and high levels of erythrocyte sedimentation rate and Creactive protein. Coombs test was positive. ANA and SSA were positive, while other autoantibodies were negative. Abdominal contrast-enhanced MRI revealed hepatomegaly and hepatic fibrosis (Fig. 2a). She was diagnosed with hypothyroidism, hepatic fibrosis, systemic lupus erythematosus and lupus nephritis. Liver biopsy was performed due to continued hepatomegaly and hepatic dysfunction and showed liver fibrosis (Fig. 2b). Renal biopsy was also done because of persistent hematuria and proteinuria and displayed moderately increased mesangial matrix and mesangial hypercellularity under the light microscope; subepithelial deposits were noted, and some mesangial changes were possibly present by electron microscopy. Immunofluorescence was positive forC1q, C3, IgA, IgM, and Fb (Fig. 2c). Oral prednisolone and hydroxychloroquine (HCQ) combined with mycophenolate mofetil (MMF) were given to her. Six months later, the level of complement was restored to normal, hematuria and proteinuria disappeared, and liver function returned to normal. The patient is currently receiving anti-TNFa (etanercept $25 \mathrm{mg} /$ week) in combination with $\mathrm{HCQ}$, low dose prednisolone and MMF. The treatment has displayed good efficacy.

Patient 2 (P2), the 5.1-year-old younger brother of P1, presented with a fever of unknown origin and had polyarthritis at age 2.6. He was initially diagnosed with polyarticular juvenile idiopathic arthritis (JIA) because of the chronic synovitis of his joints, which was found in a local hospital (Fig. 2d). He was admitted to our hospital for further assessment due to abdominal pain, diarrhea and perianal abscess after discharge from the local hospital. On admission, HLA-B27 was positive, but no significant autoantibody was detected in his serum. Under endoscopy, multiple ulcers were found on the gastrointestinal tract. The change of pathology was consistent with Crohn's disease. Therefore, the patient was diagnosed with Crohn's disease and inflammatory bowel disease-related arthritis (IBD-RA). Prednisolone, Etiasa and MTX were given to him, and his joint symptoms and intestinal symptoms disappeared gradually. $\mathrm{He}$ is currently being treated with anti-TNFo (etanercept 12.5 $\mathrm{mg} / 5$ days), Etiasa and MTX. The treatment has displayed good efficacy.

Patient 3 (P3), the father of P1 and P2, also had a history of recurrent arthralgia and anal fistula starting from 7 years of age. He refused further assessment.

\section{Family 2}

Patient 4 (P4), a 9-year-old girl, visited a local hospital complaining of a fever of unknown origin and polyarthritis at the age of 7 years. She was also diagnosed with polyarticular juvenile idiopathic arthritis (JIA) because of

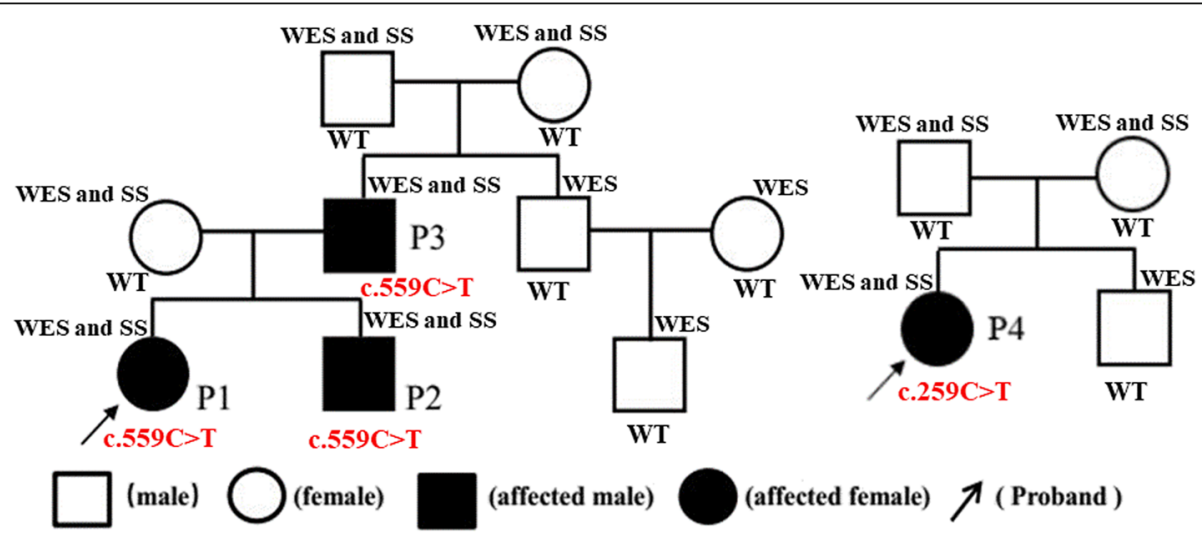

WES: whole exome sequencing, SS: Sanger sequencing, WT: wild type

Fig. 1 Spectrum of family 1 and family 2 


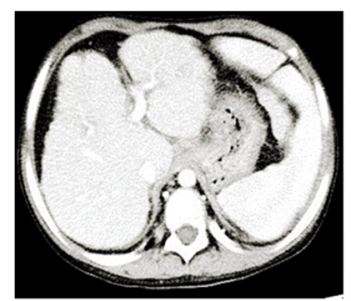

A

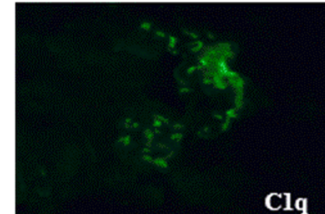

Clq

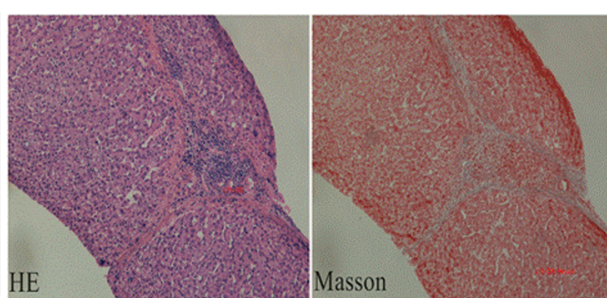

B
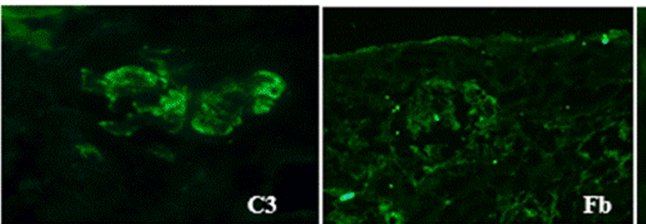

C

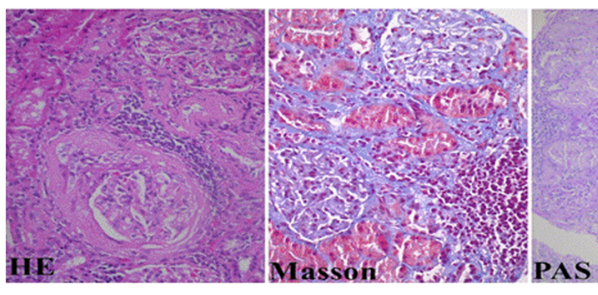

C

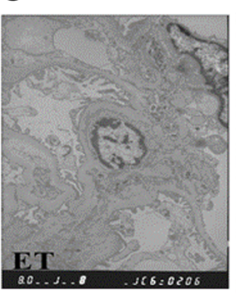
ET

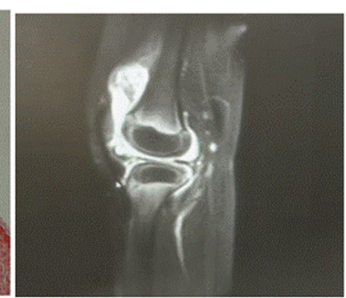

D

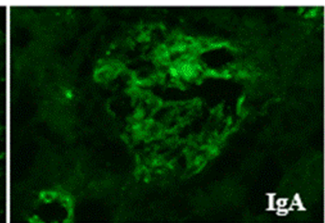

$\operatorname{IgA}$

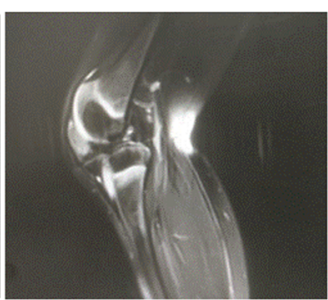

E

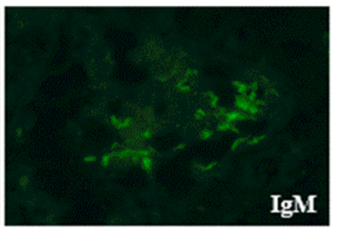

IgM

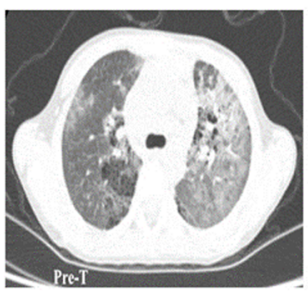

$\mathrm{F}$

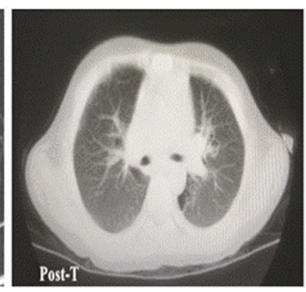

Fig. 2 a Abdominal contrast-enhanced MRI revealed hepatomegaly and hepatic fibrosis in P1. b Liver biopsy showed hepatic fibrosis by HE and Masson stain ( $\times 200)$ in P1. c Renal biopsy showed lupus nephritis type III under light $(\times 400)$, electron $(\times 11600)$ and Immunofluorescence $(\times 400)$ microscopy in P1. d Contrast-enhanced MRI revealed chronic synovitis of the knee joint in P2. e Contrast-enhanced MRI revealed chronic synovitis of the knee joint in P3. f Lung CT scan showed interstitial lung disease (ILD) in P3

the chronic synovitis of her joints (Fig. 2e). She was referred to our hospital for evaluation due to oral ulcers, cough, and positive ANA and anti-ds DNA antibodies after discharge from the local hospital. She had no relevant past medical history and no family history of rheumatic diseases. On admission, laboratory studies showed hyperferritinemia (>2000 ng/ml), hypertriglyceridemia $(5.57 \mathrm{mmol} / \mathrm{L})$, hypofibrinogenemia $(2.0 \mathrm{~g} / \mathrm{L})$, and increased levels of Alanine Aminotransferase (61
IU/L), Glutamic-oxalacetic Transaminase (97 IU/L) and lactate dehydrogenase (726 IU/L). HLA-B27 and ANA were positive for her, but no other autoantibody was detected in her serum. Lung CT scan showed interstitial lung disease (ILD) (Fig. 2f). Therefore, she was diagnosed with JIA, macrophage activation syndrome (MAS) and ILD. Voltaren, prednisolone, and CSA were given to her, and her temperature became stable while joint symptoms disappeared quickly. She is currently receiving

Table 1 Characteristics of patients with HA20

\begin{tabular}{|c|c|c|c|c|c|c|c|c|}
\hline Patient no & Family & Gender & Current age & Age at onset & Previous diagnosis & Current diagnosis & Previous treatment & Current treatment \\
\hline 1 & Family 1 & $\mathrm{~F}$ & 14.1 years & 7.0 years & $\begin{array}{l}\text { liver fibrosis } \\
\text { Hypothyroidism } \\
\text { SLE } \\
\text { Lupus nephritis }\end{array}$ & $\mathrm{HA} 20$ & $\begin{array}{l}\text { Prednisolone } \\
\text { MMF } \\
\text { Sodium levothyroxine } \\
\text { HCQ }\end{array}$ & $\begin{array}{l}\text { Prednisolone } \\
\text { MMF } \\
\text { Sodium levothyroxine } \\
\text { HCQ } \\
\text { Etanercept }\end{array}$ \\
\hline 2 & Family 1 & M & 5.1 years & 2.5 years & $\begin{array}{l}\text { Crohn's disease } \\
\text { IBD-RA }\end{array}$ & $\mathrm{HA} 20$ & $\begin{array}{l}\text { Prednisolone } \\
\text { 5-AminoSalicylicAcid } \\
\text { MTX }\end{array}$ & $\begin{array}{l}\text { Prednisolone } \\
\text { 5-AminoSalicylicAcid } \\
\text { MTX } \\
\text { Etanercept }\end{array}$ \\
\hline 3 & Family 1 & M & 38.2 years & 7.0 years & - & $\mathrm{HA} 20$ & & \\
\hline 4 & Family 2 & $\mathrm{~F}$ & 8.3 years & 6.9 years & $\begin{array}{l}\text { JIA, CTD-ILD } \\
\text { MAS }\end{array}$ & $\mathrm{HA} 20$ & $\begin{array}{l}\text { Prednisolone } \\
\text { CSA } \\
\text { Diclofenac Sodium }\end{array}$ & $\begin{array}{l}\text { Prednisolone } \\
\text { CSA } \\
\text { Diclofenac Sodium } \\
\text { Etanercept }\end{array}$ \\
\hline
\end{tabular}

SLE Systemic lupus erythematosus, IBD-RA Inflammatory bowel disease-related arthritis, CTD-ILD Connective tissue disease-related interstitial lung disease, MAS Macrophage activation syndrome, HCQ Hydroxychloroquine, MTX Methotrexate, CSA Cyclosporine A 
anti-TNF $\alpha$ (etanercept $25 \mathrm{mg} /$ week) in association with low dose prednisolone. The treatment has displayed good efficacy, and ILD was significantly improved (Fig. 2f).

The demographic and clinical features of the patients are summarized in Table 1 and Table 2, respectively. The laboratory findings of pre-therapy and post-therapy in the patients are summarized in Table 3 .

\section{Whole exome sequencing}

Whole exome sequencing (WES) was performed in two HA20 families, which included all members in Fig. 1. Methodology of WES and Sanger sequencing refers to our published work [18]. An average of $11.8 \mathrm{~Gb}$ of raw sequence data was generated with $92.65 \times$ depth of exome target regions for each individual as paired-end 150 base pair reads. $91.2 \%$ of the raw date sequencing quality was above Q30. The coverage of at least $10 \times$ and $20 \times$ of the target regions was 99.52 and $97.5 \%$ respectively.

WES revealed heterozygous c.559C > T(p.Q187X) mutation in the TNFAIP3 gene (RS:NM_006290) in P1, P2 and P3, while the mutation was not detected in other members in family 1 . The c.259C $>$ T (p.R87X) mutation in the TNFAIP3 gene (RS:NM_006290) was identified in $\mathrm{P} 4$, but the mutation was not found in her parents.

Therefore, the c.559C $>\mathrm{T}$ and c. $259 \mathrm{C}>\mathrm{T}$ mutations were de novo for P3 and P4, respectively. No mutations were detected in other genes associated with autoinflammatory diseases (see the Additional file 1) in two families.

\section{Sanger sequencing}

Sanger sequencing was used to confirm mutations identified by WES. Methodology of Sanger sequencing also refers to our published work [18]. Two mutations, c.559C $>\mathrm{T}$ and c.259C $>\mathrm{T}$ in the TNFAIP3 gene, were confirmed by Sanger sequencing in two families (Fig. 3). They were checked in mutation databases on human populations, such as ExAC Browser (http://exac.broadinstitute.org/), 1000Genomes (http://www.internationalgenome.org/), and HGMD (http://www.hgmd.cf.ac.uk/ ac/index.php). The c.259C $>\mathrm{T}$ mutation was not found in the above mutation databases.

\section{Discussion and conclusion}

In this study, we describe the clinical manifestations of four Chinese patients with HA20 from two unrelated families. Four patients all had no signs of eye and skin problems, such as uveitis, rash, folliculitis and dermal abscess. Based on clinical features, P1 was initially diagnosed with SLE, liver fibrosis and hypothyroidism. She also had no oral, genital or perineal ulcers. P2 was initially diagnosed with Crohn's disease and inflammatory bowel disease-related arthritis (IBD-RA). He had perianal abscess but no oral or genital ulcers. However, P3, the father of P1 and P2, only had mild oral ulcers, arthralgia, and archosyrinx. Therefore, three patients had different phenotypes in this family. Furthermore, signs of liver and thyroid problems were never reported before in HA20 patients in other studies.

P4 was initially diagnosed with polyarticular juvenile idiopathic arthritis (JIA) because of the chronic synovitis of her joints. Although ANA was positive, no other autoantibody was detected in her serum. She did not meet the classification criteria for SLE. However, she met the classification criteria of macrophage activation syndrome (MAS) in suspected systemic juvenile idiopathic arthritis (SJIA) due to fever, hyperferritinemia, hypertriglyceridemia and hypofibrinogenemia. She had a cough, and her lung CT scan showed ILD. ILD is one of the most common and clinically important manifestations of autoimmune diseases/connective tissue disease [19]. To date, MAS and ILD in the HA20 patients from this study were the first cases reported. Thus, clinical features were significantly different between families with HA20 in our study.

HA20 was initially identified as a Behçet's disease-like phenotype. The original description showed that all patients with HA20 had recurrent aphthous stomatitis and genital ulcers [13]. However, not all patients included in our study and other studies developed some Behçet's disease-like phenotypes [14-17], even if some patients included in our study and other studies did not have a Behçet's disease-like phenotype [15-17]. Thus, HA20 is a very heterogeneous disease. Patients presenting with Behçet's-

Table 2 Clinical features of patients with TNFAIP3 mutation

\begin{tabular}{|c|c|c|c|c|c|c|c|c|c|c|}
\hline No & Fever & Ulcers & Musculoskeletal & Cardiovascular & Intestinal & Thyroid & Liver & lung & Genotype & Mutation origin \\
\hline 1 & Yes & No & No & $\begin{array}{l}\text { pericardial } \\
\text { effusion }\end{array}$ & No & Hypothyroidism & $\begin{array}{l}\text { Hepatomegaly } \\
\text { liver fibrosis }\end{array}$ & No & $\begin{array}{l}c .559 C>T \\
\text { (p.Q187X) }\end{array}$ & Father \\
\hline 2 & Yes & No & Polyarthritis & No & $\begin{array}{l}\text { Diarrhea perianal } \\
\text { abscess } \\
\text { Crohn's disease }\end{array}$ & No & No & No & $\begin{array}{l}\text { c.559C > T } \\
\text { (p.Q187X) }\end{array}$ & Father \\
\hline 3 & No & Oral & Arthralgia & No & Archosyrinx & No & No & No & $\begin{array}{l}\text { c.559C > T } \\
\text { (p.Q187X) }\end{array}$ & De novo \\
\hline 4 & Yes & No & Polyarthritis & No & No & No & No & $\begin{array}{l}\text { Cough } \\
\text { ILD }\end{array}$ & $\begin{array}{l}\text { c. } 259 C>T \\
(p . R 87 X)\end{array}$ & De novo \\
\hline
\end{tabular}


Table 3 Laboratory findings of patients with HA20

\begin{tabular}{|c|c|c|c|c|c|c|c|}
\hline \multirow[t]{2}{*}{ Testing } & \multicolumn{2}{|l|}{ Case 1} & \multicolumn{2}{|l|}{ Case 2} & \multicolumn{2}{|l|}{ Case 4} & \multirow{2}{*}{$\begin{array}{l}\text { Normal } \\
\text { range }\end{array}$} \\
\hline & Pretherapy & posttherapy & Pretherapy & posttherapy & Pretherapy & posttherapy & \\
\hline ESR $(\mathrm{mm} / \mathrm{h})$ & 89.0 & 19 & 35 & 11 & 79.0 & 9.0 & $0-20$ \\
\hline CRP (mg/dl) & 48.0 & $<8$ & 89 & $<8$ & 48.0 & $<8$ & $<8$ \\
\hline Hemoglobin (g/dl) & 89.2 & 115.0 & 85.2 & 129.0 & 117 & 142 & $110-160$ \\
\hline Leukocyte (/mm3) & 3.5 & 6.8 & 11.2 & 13.9 & 13.5 & 13.5 & $4-10$ \\
\hline Thrombocyte (/mm3) & 81.0 & 118.0 & 205 & 304 & 528 & 238 & $100-300$ \\
\hline TNF-a(pg/ml) & 22.1 & 4.2 & & & & & $0.0-8.1$ \\
\hline $\mathbb{I L}-6$ & 46.62 & 8.62 & 49.6 & 5.77 & 31.51 & 6.21 & $<7$ \\
\hline Ferritin & 111.6 & 33.8 & 447.0 & 31.0 & $>2000$ & 237.3 & $0.94-71.7$ \\
\hline $\mathrm{C} 3(\mathrm{~g} / \mathrm{L})$ & 0.22 & 0.66 & 1.65 & 1.58 & 1.87 & 1.42 & $0.67-1.76$ \\
\hline$C 4(g / L)$ & 0.06 & 0.1 & 0.56 & 0.72 & 0.3 & 0.36 & $0.1-0.4$ \\
\hline $\mathrm{CH} 50(\mathrm{U} / \mathrm{ml})$ & 10.0 & 26 & 66 & 58 & 35 & 26 & $23-46$ \\
\hline ANA & + & + & - & - & + & - & Negative \\
\hline Anti-dsDNA & + & - & - & - & - & - & Negative \\
\hline
\end{tabular}

like disease or other features of autoinflammatory and autoimmune disease starting in early childhood should be screened for the TNFAIP3 mutation, especially if there is a family history of similar symptoms, as the clinical course and response to the treatment of this genetic disorder differs from common Behçet's disease.

A20 functions as a negative regulator of the nuclear factor $k B(N F-k B)$ pathway and modulates immune responses by preventing excessive activation of NF- $k B$ in response to a variety of external stimuli [20]. It is structurally divided into two types of domains - the N-terminal Ovarian tumor (OTU) domain and the C-terminal domain containing 7 zinc finger motifs $(\mathrm{ZnF1}-\mathrm{ZnF7})$ [21]. It harbors a deubiquitination enzyme domain and activates multiple mechanisms to antagonize ubiquitination upstream of the NF-kB essential modulator (NEMO), a regulatory subunit of the IkB kinase (IKK) complex [4]. The IKK complex has 2 catalytic subunits (IKKa and IKKb)
c.559C $>$ T (chr6: 138196897)

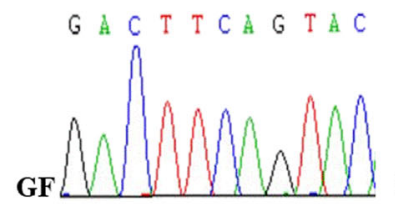

$G A C T T C A G T A C$
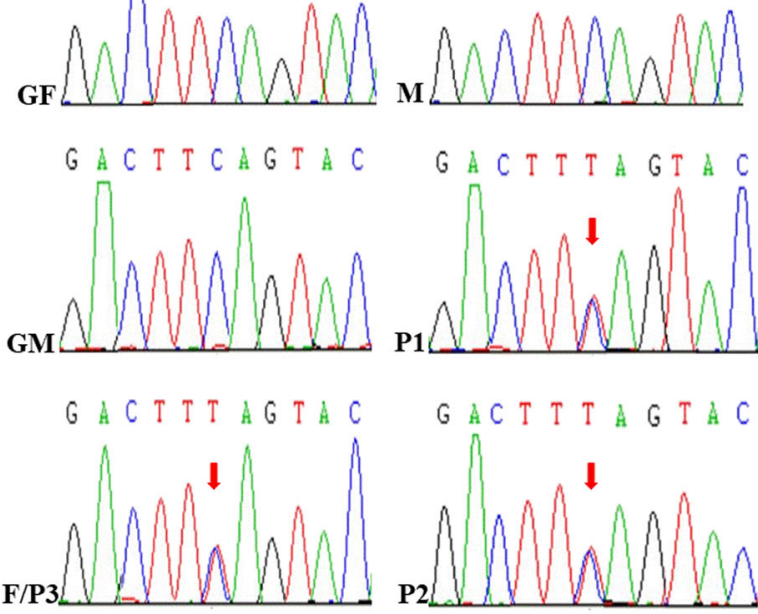

Family 1(P1, P2 and P3)
c.259C $>$ T (chr6: 138192632)

G G T G T C G A G A A

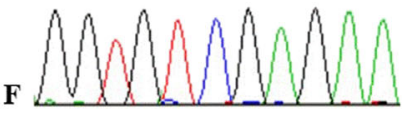

G G T G T C GA GA A

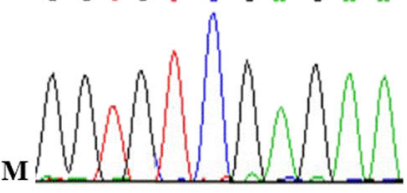

G G T G T T G A G A A

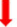

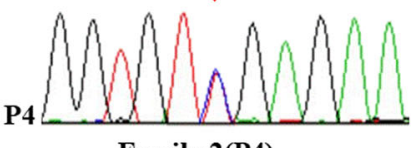

Family 2(P4)

Fig. 3 Mutation analysis in TNFAIP3 gene in family 1 and family 2. P: patient; F: father; M: mother; GF: grandfather; GM: grandfather 
and a subunit that regulates the canonical NF-kB pathway (NEMO/IKKg). The IKK regulates the noncanonical pathway by IKKa [22]. The ubiquitin-induced recruitment of A20 to NEMO can downregulate IKK activation by blocking IKK phosphorylation. On activation, IKK phosphorylates the inhibitory IkBa protein, leading to its degradation and dissociation from NF-kB, after which it translocates to the nucleus [23]. Hence, A20 deficiency leads to the activation of the NF-kB pathway. Both a mutation in the TNFAIP3 gene in the $\mathrm{N}$-terminal domain or the $\mathrm{C}$ terminal domain can cause the loss of A20 function [1417]. Approximately 10 different disease-causing mutations of the TNFAIP3 gene have been reported in various populations (http://www.hgmd.cf.ac.uk/, last updated April, 2018). In our study, WES revealed that a heterozygous c.559C > T(p.Q187X) mutation in the TNFAIP3 gene cosegregates with the disease in three patients of family 1 . The mutation was confirmed by Sanger sequencing, but it was reported by other study [16]. By sequence analysis in family 1, we found that P3 had this de novo mutation and transmitted it to his children. Interestingly, the three patients had the same genotype of the TNFAIP3 gene but had different phenotypes. The heterozygous c. $259 \mathrm{C}>\mathrm{T}$ (p.R87X) mutation in the TNFAIP3 gene was detected by WES and confirmed by Sanger sequencing in family 2 . Sequence analysis in family 2 showed that the p.R87X mutation is a de novo mutation, where a nonsense mutation leads to the truncation of A20. The p.R87X mutation was first reported in our study. The p.Q187X and p.R87X mutations are both located in OUT domains, which controlled NF- $\mathrm{BB}$ signaling by deubiquitinating receptorinteracting protein (RIP) 1, RIP2 and TNF receptorassociated factor (TRAF) [24].

Here, we provide four HA20 patients with novel features of considerable existing evidence implicating novel mutations in the TNFAIP3 gene. Our study expands the phenotype and genotype spectrum of HA20.

HA20 is a new autoinflammatory disease caused by heterozygous loss-of-function mutations in TNFAIP3. These mutations cause insufficient DUB activity of A20 and lead to an increased NF- $\mathrm{KB}$ signaling and phosphorylation of c-Jun N-terminal kinase and p38 mitogenactivated protein kinases (MAPKs). Clinical features were significantly different between families with HA20, even between numbers with the same TNFAIP3 mutation.

\section{Additional file}

Additional file 1: Genes associated with auto-inflammatory diseases. (DOCX $18 \mathrm{~kb}$ )

\section{Abbreviations}

ANA: Antinuclear antibody; CSA: Cyclosporine A; HA20: A20 haploinsufficiency; HCQ: Hydroxychloroquine; IBD-RA: Inflammatory bowel disease-related arthritis; IKK: The IkB kinase; ILD: Interstitial lung disease;
JA: Juvenile idiopathic arthritis; MAPKs: Mitogen-activated protein kinases; MAS: Macrophage activation syndrome; MMF: Mycophenolate mofetil; NEMO: NF-kB essential modulator; NF-kB: The nuclear factor kB; OUT: The Nterminal Ovarian tumor; SJIA: Systemic juvenile idiopathic arthritis;

SSA: Sjogren's syndrome A antigen; WES: Whole exome sequencing

\section{Acknowledgements}

The research team is thankful to our patients and their parents.

\section{Authors' contributions}

LS conceptualized the study. G-mL performed the experiment. HX, G-mL, W$\mathrm{zG}, \mathrm{H}-\mathrm{mL}$ and $\mathrm{LS}$ acquired the data. G-MI, B-bW and CL analyzed the data. G$\mathrm{mL}$ and $\mathrm{LS}$ contributed to data interpretation and manuscript preparation.

All authors read and approved the final manuscript.

\section{Funding}

There are no sources of funding to be reported for this study.

\section{Availability of data and materials}

All data generated or analyzed during this study are included in this published article.

\section{Ethics approval and consent to participate}

This study is followed with all criteria adhered to the Declaration of Helsinki. Ethics board approval and consent was obtained for this work from the Ethics Committee at the Children's Hospital of Fudan University, Shanghai, China (ekyy-2016-23).

\section{Consent for publication}

All people including the patient's parents in two families and their grandparents in family 1 gave a written consent for publication on a local form approved by the Medical Ethics Committee of our institution.

\section{Competing interests}

The authors declare that they have no competing interests.

\section{Author details}

${ }^{1}$ Department of Rheumatology, Children's Hospital of Fudan University, 399 Wan-yuan road, Shanghai 201102, China. ${ }^{2}$ Medical Transformation Centre, Children's Hospital of Fudan University, 399 Wan-yuan road, Shanghai 201102, China.

Received: 18 January 2019 Accepted: 30 June 2019 Published online: 12 July 2019

References

1. Dixit VM, Green S, Sarma V, Holzman LB, Wolf FW, O'Rourke K, et al. Tumor necrosis factor-alpha induction of novel gene products in human endothelial cells including a macrophage-specific chemotaxin. J Biol Chem. 1990;265:2973-8.

2. Coornaert B, Carpentier I, Beyaert R. A20: central gatekeeper in inflammation and immunity. J Biol Chem. 2009;284:8217-21.

3. Wertz IE, O'Rourke KM, Zhou H, Eby M, Aravind L, Seshagiri S, et al. De-ubiquitination and ubiquitin ligase domains of A20 downregulate NF-kappaB signalling. Nature. 2004;430:694-9.

4. Graham RR, Cotsapas C, Davies L, Hackett R, Lessard CJ, Leon JM, et al. Genetic variants near TNFAIP3 on 6q23 are associated with systemic lupus erythematosus. Nat Genet. 2008;40:1059-61.

5. Musone SL, Taylor KE, Lu TT, Nititham J, Ferreira RC, Ortmann W, et al. Multiple polymorphisms in the TNFAIP3 region are independently associated with systemic lupus erythematosus. Nat Genet. 2008;40:1062-4

6. Adrianto I, Wen F, Templeton A, Wiley G, King JB, Lessard CJ, et al. Association of a functional variant downstream of TNFAIP3 with systemic lupus erythematosus. Nat Genet. 2011;43:253-8.

7. Sisto M, Lisi S, Lofrumento DD, Ingravallo G, Maiorano E, D'Amore M. A failure of TNFAIP3 negative regulation maintains sustained NF-KB activation in Sjögren's syndrome. Histochem Cell Biol. 2011;135:615-25.

8. Consortium WTCC. Genome-wide association study of 14,000 cases of seven common diseases and 3,000 shared controls. Nature. 2007;447:661-78. 
9. Plenge RM, Cotsapas C, Davies L, Price AL, de Bakker Pl, Burtt NP, et al. Two independent alleles at $6 q 23$ associated with risk of rheumatoid arthritis. Nat Genet. 2007;39:1477-82.

10. Thomson W, Barton A, Ke X, Eyre S, Hinks A, Bowes J, et al. Rheumatoid arthritis association at 6q23. Nat Genet. 2007;39:1431-3.

11. Fukaya M, Brorsson CA, Meyerovich K, Catrysse L, Delaroche D, Vanzela EC, et al. A20 inhibits $\beta$-cell apoptosis by multiple mechanisms and predicts residual $\beta$-cell function in type 1 diabetes. Mol Endocrinol. 2016;30:48-61.

12. Tejasvi T, Stuart PE, Chandran V, Voorhees JJ, Gladman DD, Rahman P, et al. TNFAIP3 gene polymorphisms are associated with response to TNF blockade in psoriasis. J Invest Dermatol. 2012;132:593-600.

13. Zhou Q, Wang H, Schwartz DM, Stoffels M, Park YH, Zhang Y, et al. Loss-offunction mutations in TNFAIP3 leading to A20 haploinsufficiency cause an early-onset autoinflammatory disease. Nat Genet. 2016;48:67-73.

14. Berteau F, Rouviere B, Delluc A, Nau A, Le Berre R, et al. Autosomic dominant familial Behçet disease and haploinsufficiency A20: A review of the literature. Autoimmun Rev. 2018;17:809-15.

15. Aeschlimann FA, Batu ED, Canna SW, Go E, Gül A, Hoffmann P, et al. A20 haploinsufficiency (HA20): clinical phenotypes and disease course of patients with a newly recognised NF-kB-mediated autoinflammatory disease. Ann Rheum Dis. 2018;77:728-35.

16. Duncan CJA, Dinnigan E, Theobald R, Grainger A, Skelton AJ, Hussain R, et al. Early-onset autoimmune disease due to a heterozygous loss-offunction mutation in TNFAIP3 (A20). Ann Rheum Dis. 2018;77:783-6.

17. Shigemura T, Kaneko N, Kobayashi N, Kobayashi K, Takeuchi Y, Nakano N, et al. Novel heterozygous C243Y A20/TNFAIP3 gene mutation is responsible for chronic inflammation in autosomal-dominant Behçet's disease. RMD Open. 2016;2:e000223.

18. Li GM, Cao Q, Shen Q, Sun L, Zhai YH, Liu HM, et al. Gene mutation analysis in 12 Chinese children with congenital nephrotic syndrome. BMC Nephrol. 2018;19(1):382.

19. Solomon JJ, Fischer A. Connective tissue disease-associated interstitial lung disease: a focused review. J Intensive Care Med. 2015:30:392-400.

20. Aksentijevich I, Zhou Q. NF-kB pathway in autoinflammatory diseases: dysregulation of protein modifications by ubiquitin defines a new category of autoinflammatory diseases. Front Immunol. 2017;8:399.

21. Verstrepen L, Verhelst K, van Loo G, Carpentier I, Ley SC, Beyaert R. Expression, biological activities and mechanisms of action of A20 (TNFAIP3). Biochem Pharmacol. 2010;80:2009-20.

22. Shembade N, Ma A, Harhaj EW. Inhibition of NF-kappaB signaling by A20 through disruption of ubiquitin enzyme complexes. Science. 2010;327:1135-9.

23. Bellail AC, Olson JJ, Yang X, Chen ZJ, Hao C. A20 ubiquitin ligase-mediated polyubiquitination of RIP1 inhibits caspase-8 cleavage and TRAlL-induced apoptosis in glioblastoma. Cancer Discov. 2012;2:140-55.

24. Li L, Soetandyo N, Wang Q, Ye Y. The zinc finger protein A20 targets TRAF2 to the lysosomes for degradation. Biochim Biophys Acta. 2009;1793:346-53.

\section{Publisher's Note}

Springer Nature remains neutral with regard to jurisdictional claims in published maps and institutional affiliations.

Ready to submit your research? Choose BMC and benefit from:

- fast, convenient online submission

- thorough peer review by experienced researchers in your field

- rapid publication on acceptance

- support for research data, including large and complex data types

- gold Open Access which fosters wider collaboration and increased citations

- maximum visibility for your research: over $100 \mathrm{M}$ website views per year

At $\mathrm{BMC}$, research is always in progress.

Learn more biomedcentral.com/submissions 